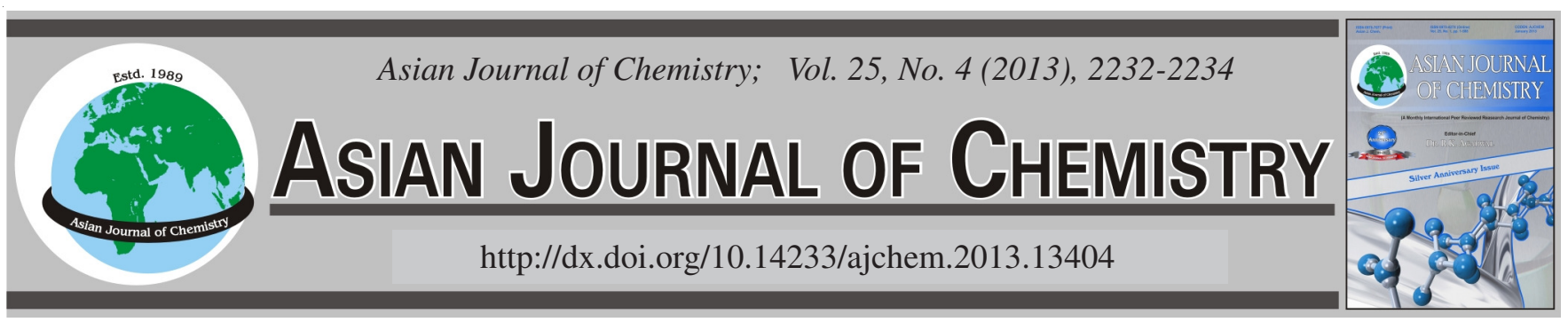

\title{
Silver Doped Poly(lysine) Polymer Film Modified \\ Electrode for Selective Determination of Norepinephrine
}

\author{
XIA Li* and XIAOYANG YANG
}

Department of Chemistry and Chemical Engineering, Heze University, Daxue Road, Heze 274015, Shandong Province, P.R. China

*Corresponding author: Tel: +86 13508981328; E-mail: chenmeifeng456@yahoo.com.cn

(Received: 7 January 2012;

Accepted: 17 October 2012)

AJC-12318

\begin{abstract}
The silver doped poly(lysine) modified electrode was prepared by cyclic voltammetric method. The modified electrode was shown to possess an excellent selective electrocatalytical effect on the redox of norepinephrine and further used to determine norepinephrine in the presence of uric acid and ascorbic acid in $\mathrm{pH} 6.0$ phosphate buffer solution. The reductive peak current (Ipc) showed a linear relationship with the concentrations (C) of norepinephrine in the range of $1.13 \times 10^{-7}-1.13 \times 10^{-4} \mathrm{~mol} \mathrm{~L}^{-1}$ and a detection limit was $5.66 \times 10^{-8} \mathrm{~mol} \mathrm{~L}^{-1}$. The modified electrode is high sensitivity, selectivity, stability and has been successfully applied to analyze norepinephrine. The method has high sensitivity, selectivity, stability and practical application of the modified electrode was demonstrated by analyzing injection samples of norepinephrine in the presence of uric acid and ascorbic acid in $\mathrm{pH} 6.0$ phosphate buffer solution.
\end{abstract}

Key Words: Norepinephrine, Silver doped poly(lysine), Modified electrode, Polymer film.

\section{INTRODUCTION}

Norepinephrine (NE) is one of the important catecholamine neurotransmitters in the mammalian central nervous system. Low levels of norepinephrine are associated with pain, depression and appetite. Recent reports have indicated that norepinephrine accelerates HIV replication via protein kinase ${ }^{1,2}$. Various methods for determination of norepinephrine have been described ${ }^{3-7}$. But these methods often suffer from the disadvantages of low sensitivity and/or a complicated immobilized procedure. In recent years, modified electrodes have been used for electrochemical analysis of norepinephrine ${ }^{8,9}$. Poly(lysine) (Plys) contains amino groups which can produce ammonia cation radical by electrochemical oxidation, then the radical cation formed $\mathrm{C}-\mathrm{N}$ chemical bond on carbon surfaces which creating a stable polymer membrane. It has great application value as an electrochemical sensor. Silve nanoparticles have attracted extensive attention and research, because it has a unique electrical, magnetic, optical, thermal properties and catalytic activity. This makes it widely used in optoelectronic devices, electric catalysis and biological sensor ${ }^{10-12}$. Amino acid and silver have synergistic effect; the composite membrane for norepinephrine has better catalytic effect. The electrode has advantages of simple preparation, quick response, easy to use for the quantitative analysis of norepinephrine and injection samples with satisfactory results for the first time.

\section{EXPERIMENTAL}

Norepinephrine was purchased from the National Institute for the Control of Pharmaceutical and Biological Products (Beijing, China). Ascorbic acid and uric acid were obtained from Beijing Chemical Factory (China). All other chemical reagents (analytical-reagent grade) were obtained from Beijing Chemical Reagent Company (Beijing China). Phosphate buffer solutions were prepared by mixing the stock solutions of 0.2 mol L $\mathrm{L}^{-1}$ disodium hydrogen phosphate and $0.1 \mathrm{~mol} \mathrm{~L}^{-1}$ citric acid. All aqueous solutions were prepared in double distilled water.

CHI 660C Electrochemical Workstation (CH Instruments, Shanghai Chenhua Instrument Corporation, China), was used for electrochemical measurements. A conventional threeelectrode system was employed with a bare or modified glassy carbon electrode ( $3 \mathrm{~mm}$ in diameter) as the working electrode, a platinum wire electrode as the counter electrode and an $\mathrm{Ag}$ / $\mathrm{AgCl}$ electrode as reference electrode. All potentials reported in this paper were referenced to the $\mathrm{Ag} / \mathrm{AgCl}$ electrode. PHS3B was applied by Shanghai Precision Scientific Instrument Co., Ltd. (China) and KQ-100 ultrasonic cleaner was from Kunshan Ultrasonic Instrument Factory (China).

Electrode preparation and modification: The bare glassy carbon electrode (GCE, $\Phi=3 \mathrm{~mm}$ ) was polished before each experiment with gold sand paper and $0.05 \mu \mathrm{m}$ alumina powder, respectively, rinsed thoroughly with doubly distilled 
water between each polishing step, then washed successively with 1:1 nitric acid, acetone and doubly distilled water in ultrasonic bath and dried in air. The Ag-Plys/GCE was obtainted by cyclic voltammetric $(\mathrm{CV})$ in the potential range between -1.0 and $2.2 \mathrm{~V}$ for 10 cycles at a scan rate of $100 \mathrm{mV}$ $\mathrm{s}^{-1}$. The silver doped lysine modified solution was made up of $0.01 \mathrm{~mol} \mathrm{~L}^{-1} \mathrm{AgNO}_{3}$, nitric acid and water (1:1, v/v), $0.15 \mathrm{~mol}$ $\mathrm{L}^{-1} \mathrm{KNO}_{3}, 0.01$ mol L ${ }^{-1}$ lysine.

Analytical procedure: Under optimal conditions, a series of different concentrations of norepinephrine were investigated by CV. A three-electrode system was used, including a GME as working electrode, a platinum electrode as counter electrode and $\mathrm{Ag} / \mathrm{AgCl}$ as a reference electrode. Cyclic voltammograms (CVs) of norepinephrine were recorded. The glassy carbon electrode was treated in PBS $(\mathrm{pH}$ 6.0) by repetitive scanning in the potential range between -0.4 and $0.6 \mathrm{~V}$ at a scan rate of $100 \mathrm{mV} \mathrm{s}^{-1}$ so as to no record and used again.

\section{RESULTS AND DISCUSSION}

Optimization of electrochemical polymerization: The electrochemical polymerization of silver doped polylysine at electrode is a complex process and is shown in Fig. 1. Electrochemical behaviours of the Ag-Plys/GCE is affected by polymerization conditions, such as potential range, cycle and scanning rate. After many experiments by cyclic voltammogram, the Ag-Plys/GCE was obtained by cyclic voltammogram in the potential range between -1.0 and $2.2 \mathrm{~V}$ for 10 cycles at a scan rate of $100 \mathrm{mV} \mathrm{s}^{-1}$.

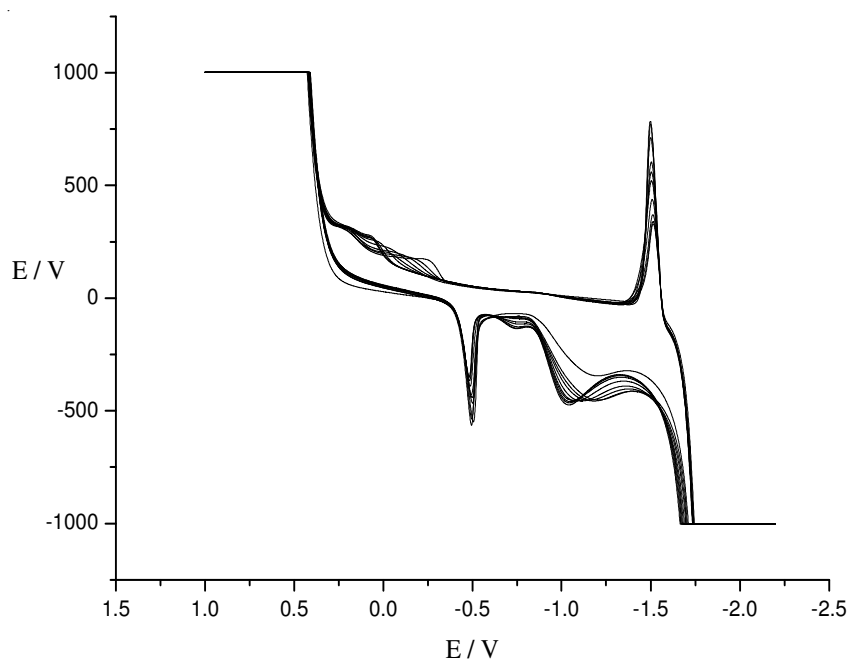

Fig. 1. Cyclic voltammetric curves of metal-silver and lysine in polymerization process

Electrochemical behaviours of norepinephrine on the Ag-Plys/GCE: Fig. 2 shows the cyclic voltammograms of 1.0 $\times 10^{-5} \mathrm{~mol} \mathrm{~L}^{-1}$ norepinephrine in PBS (6.0) at GCE, Plys/GCE and Ag-Plys/GCE. The peak current intensity at Ag-Plys/GCE was increased and in contrast the peak current is near zero at GCE. The redox peak currents are Ipa $=-7.98 \mu \mathrm{A}, \mathrm{Ipc}=6.44$ $\mu \mathrm{A}$ and Ipa $=-16.14 \mu \mathrm{A}, \mathrm{Ipc}=9.0 \mu \mathrm{A}$ at the Plys $/ \mathrm{GME}$ and Ag-Plys/GME, which confirms that the Ag-Plys/GCE has excellent electrocatalytic activity to norepinephrine.

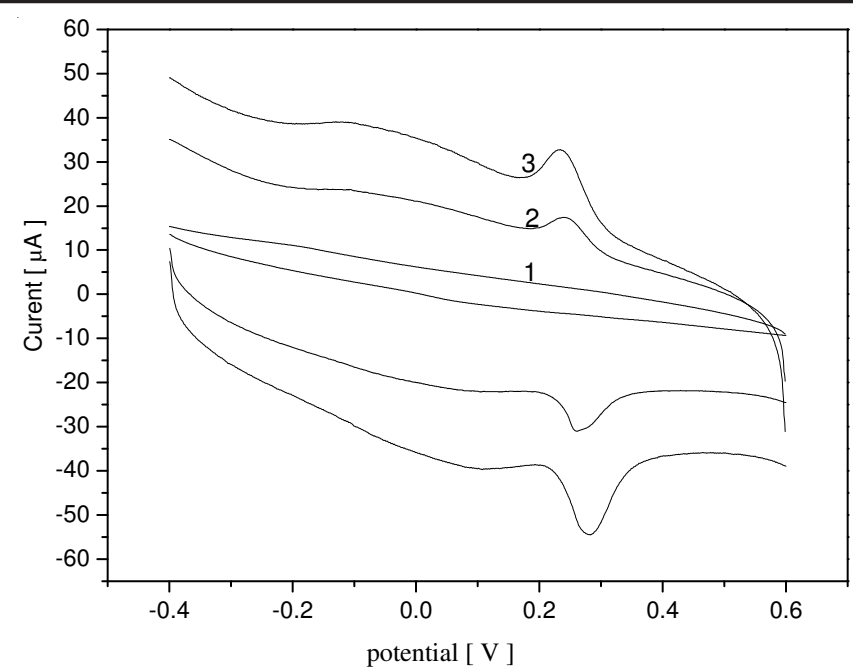

Fig. 2. Cyclic voltammograms of norepinephrine at GCE (1), Lys/GCE (2) and Ag-Plys/GCE (3) PBS (pH 6.0)

\section{Optimization conditions of the determination of norepi-} nephrine at Ag-Plys modified electrode

Effect of solution pH: The effect of the medium's pH (2.2-8.0) on the electrochemical signal was analyzed (Fig. 3). Table-1 shows the important influence of $\mathrm{pH}$ on the redox reaction of norepinephrine at the Ag-Plys/GCE. As we can see, with increasing $\mathrm{pH}$ value of the solution the redox currents increased and the redox peak negatively shifted. The relationship between potential and $\mathrm{pH}$ can be described using the following equation: $\mathrm{E}_{\mathrm{pa}}=0.64-0.06 \mathrm{pH}, \mathrm{R}=0.9925$ and $\mathrm{E}_{\mathrm{pc}}=$ $0.58-0.057 \mathrm{pH}, \mathrm{R}=0.9992$.

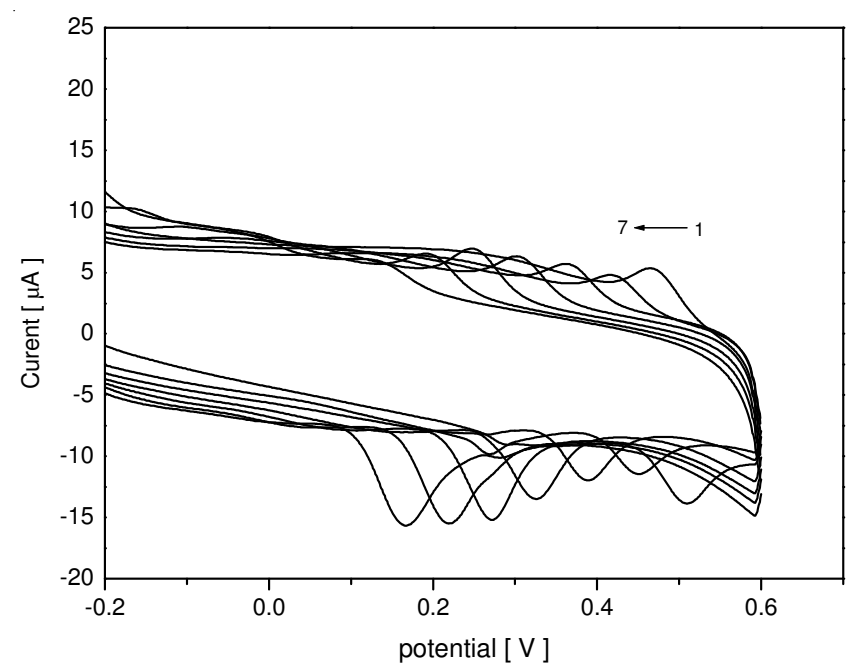

Fig. 3. Effects of solution $\mathrm{pH}$ at Ag-Plys/GCE. $\mathrm{pH}$ from 1 to 7: 2.2, 3.0, $4.0,5.0,6.0,7.0,8.0$, respectively

TABLE-1

\begin{tabular}{cccccccc}
\multicolumn{7}{c}{ TABLE-1 } \\
\hline $\mathrm{pH}$ & 2.2 & 3.0 & 4.0 & 5.0 & 6.0 & 7.0 & 8.0 \\
\hline $\mathrm{Ipa}(\mu \mathrm{A})$ & -4.22 & -4.87 & -9.77 & -23.28 & -25.02 & -15.87 & -12.00 \\
$\mathrm{Ipc}(\mu \mathrm{A})$ & 2.53 & 3.37 & 6.27 & 8.65 & 9.80 & 8.09 & 4.81 \\
\hline
\end{tabular}

Effect of scan rate and stirring time: Fig. 4 is the cyclic voltammograms of norepinephrine at GME with different scan rates. We can see that the oxidation potential slightly shifts in 


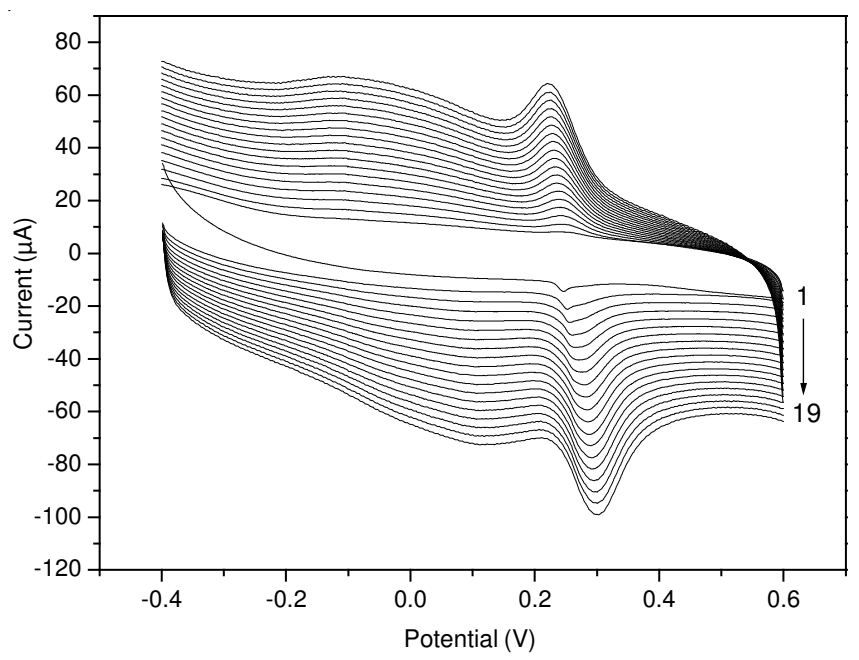

Fig. 4. Effects of scan rate. Scan rate from 1 to 19: 40, 60, 80, 100, 120, $140,160,180,200,220,240,260,280,300,320,340,360,380$ and $400 \mathrm{mV} / \mathrm{s}$, respectively

the positive direction with the increase of scan rate. The redox peak currents linearly increased with the scan rates ranging from 40-400 $\mathrm{mV} \mathrm{s}^{-1}$. Ipa $=-2.14 \times 10^{-6}-6.87 \times 10^{-8} \mathrm{v}, \mathrm{R}=$ 0.9987 and $\mathrm{Ipc}=-2.35 \times 10^{-6}+9.07 \times 10^{-8} \mathrm{v}, \mathrm{R}=0.9996$, suggesting that the electrochemical behaviours of norepinephrine on GME is an adsorption process. Due to the adsorption process, stirring time should be an important factor for the accumulation of norepinephrine at GME. The peak current increases as stirring time increases and reaches its maximum value at $1 \mathrm{~min}$. Therefore, $1 \mathrm{~min}$ was used as the accumulation time in this study.

Effect of norepinephrine concentration and detection limit: The reductive peak current at GME was proportional to the concentration of norepinephrine in PBS $(\mathrm{pH}=6.0)$, which is $1.13 \times 10^{-7}-1.13 \times 10^{-4} \mathrm{~mol} \mathrm{~L}^{-1}$, with the detection limit of $5.66 \times 10^{-8} \mathrm{~mol} \mathrm{~L}{ }^{-1}$. The linear regression equation is $\mathrm{Ipc}=$ $1.61 \times 10^{-6}+0.069 \mathrm{c}\left(\mathrm{mol} \mathrm{L}^{-1}\right)$, with a correlation coefficient of $\mathrm{R}=0.9995$.

Interference studies: It was found that the interference problem could be resolved by using this modified electrode in PBS ( $\mathrm{pH}$ 6.0). As shown in Fig. 5, norepinephrine has a pair of redox peaks, but ascorbic acid and uric acid have no reductive peaks at GME from -0.4 to $0.6 \mathrm{~V}$.

In addition, no interference has been found when including up to 100 times of $\mathrm{K}^{+}, \mathrm{Na}^{+}, \mathrm{NH}_{4}{ }^{+}, \mathrm{Ca}^{2+}, \mathrm{Mg}^{2+}, \mathrm{Cl}^{-}$, alanine and 10 times of glucose and tartaric acid also.

Real samples analysis: The present method was used for the determination of norepinephrine in three pharmaceutical injections from different batches and the recoveries were calculated according to the reductive peak currents. The results are listed in Table- 2 .

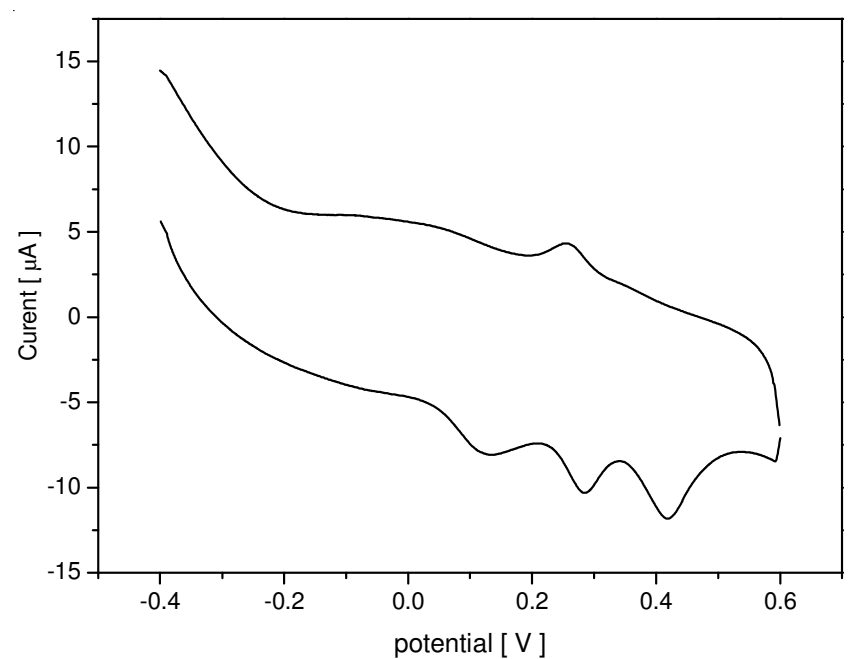

Fig. 5. Cyclic voltammograms of a mixture of norepinephrine, uric acid and ascorbic acid

TABLE-2

RESULT OF DETERMINATION OF NOREPINEPHRINE IN INJECTION SAMPLE $(\mathrm{n}=6)$

\begin{tabular}{ccccc}
\hline No & $\begin{array}{c}\text { Found } \\
\left(\mathrm{mol} \mathrm{L}^{-1}\right)\end{array}$ & $\begin{array}{c}\text { Std. added } \\
\left(\mathrm{mol} \mathrm{L}^{-1}\right)\end{array}$ & $\begin{array}{c}\text { Total found } \\
\left(\mathrm{mol} \mathrm{L}^{-1}\right)\end{array}$ & $\begin{array}{c}\text { Recovery } \\
(\%)\end{array}$ \\
\hline 1 & $1.13 \times 10^{-5}$ & $2.95 \times 10^{-5}$ & $4.01 \times 10^{-5}$ & 97.7 \\
2 & $7.26 \times 10^{-6}$ & $2.95 \times 10^{-5}$ & $3.66 \times 10^{-5}$ & 99.4 \\
3 & $4.73 \times 10^{-6}$ & $2.95 \times 10^{-5}$ & $3.43 \times 10^{-5}$ & 100.2 \\
\hline
\end{tabular}

\section{ACKNOWLEDGEMENTS}

This project is supported by the Shandong City High School Science and Technology Fund Planning Project of (J10LB64) and the Scientific Research Foundation of Heze University (XYJJKJ-4).

\section{REFERENCES}

1. D. Voet and J.G. Voet, Biochemistry, Wiley, New York, end. 2 (1995).

2. S.W. Cole, Y.D. Korin, J.L. Fahey and J.A. Zack, J. Immunol., 161, 610 (1988).

3. E. Brandsteterova, K. Krajnak and I. Skacani, Pharmazie, 50, 825 (1995).

4. P.S. Doshi and D.J. Edward, J. Chromatogr. A, 210, 505 (1981).

5. C.L. Guan, J. Quyang, Q.L. Li and B.H. Liu, Talanta, 50, 1197 (2000).

6. M. Zhu, X.M. Huang, J.Li and H.X. Shen, Anal. Chim. Acta, 357, 261 (1997).

7. F.B. Zhu, Talanta, 34, 810 (1987)

8. H. Beitollahi and I. Sheikhshoaie, J. Electroanal. Chem., 661, 336 (2011).

9. R.N. Goyal and S. Bishnoi, Talanta, 84, 78 (2011).

10. Y.W.C. Cao, R. Jin and C.A. Mirkin, Science, 297, 1536 (2002).

11. R. Elghanian, J.J. Storhoff, R.C. Mucic, R.L. Letsinger and C.A. Mirkin, Science, 277, 1078 (1997).

12. P.V. Kamat, J. Phys. Chem. B, 106, 7729 (2002). 